\title{
Imaginologia odontológica no processo de identificação humana: relato de caso pericial
}

Dental imaging in the process of human identification: expert case report

Imágenes dentales en el proceso de identificación humana: reporte de caso pericial

Milena Norões Viana GADELHA ${ }^{1}$

Rafaella Bandeira de Melo Souza CAVALCANTI ${ }^{2}$

Marília Norões Viana GADELHA ${ }^{3}$

Christian Abreu STIBICH ${ }^{4}$

Mathias Antonio Costa de SOUSA ${ }^{2}$

Ivynna Martins Marinho MORAIS ${ }^{5}$

Carolina Barbosa Lopes de LIMA $^{5}$

Joab Cabral RAMOS ${ }^{6}$

Ana Tatiana GONZALEZ ${ }^{7}$

Julierme Ferreira ROCHA ${ }^{2}$

Abrahão Alves de OLIVEIRA FILHO²

Camila Helena Machado da Costa FIGUEIREDO²

Manuella Santos Carneiro ALMEIDA ${ }^{2}$

${ }^{1}$ Departamento de Medicina Legal de João Pessoa, 58071-620 João Pessoa - PB, Brasil

${ }^{2}$ Curso de Odontologia - Universidade Federal de Campina Grande (UFCG), 58708-110 Patos - PB, Brasil

${ }^{3}$ Curso de Medicina - Faculdade de Ciências Médicas da Paraíba. 58106-402 João Pessoa - PB, Brasil

${ }^{4}$ Instituto Médico Legal Afrânio Peixoto (IML), 20220-310 Rio de Janeiro - RJ, Brasil

${ }^{5}$ Curso de Odontologia - UNIESP - Centro Universitário, 58109-303 Cabedelo - PB, Brasil

${ }^{6}$ Departamento de Diagnóstico Oral - Faculdade de Odontologia de Piracicaba (FOP), UNICAMP 13414-903 Piracicaba - SP, Brasil

${ }^{7}$ Associação Brasileira de Odontologia - Seção Paraíba 58040-490 João Pessoa - PB, Brasil

\section{Resumo}

Introdução: A imaginologia odontológica é de grande relevância para a identificação humana, sendo frequentemente utilizada pela Odontologia Legal para este fim. O correto arquivamento dos exames de imagem nos prontuários dos pacientes permite a comparação de dados ante e post mortem. Objetivo: O presente trabalho objetivou descrever a determinação da identificação de um indivíduo carbonizado por meio da imaginologia odontológica. Relato de caso: As documentações fornecidas pela família da vítima foram uma foram confrontadas com aquelas obtidas pelas radiografias periapicais dos dentes realizadas pelos peritos. Foram encontrados os seguintes pontos coincidentes após o confronto das informações entre os exames ante-mortem e post-mortem: giroversão dos dentes 34, 43 e 44; aposição de dentina secundária nas câmaras pulpares dos dentes 36, 37, 46, 47 e 48; cárie oclusal do dente 36 e trabeculado ósseo com características anatômicas individuais em região de molares inferiores nos lados direito e esquerdo, resultando em uma identificação positiva. Conclusão: Assim, conclui-se que o confronto entre as radiografias ante-mortem e post-mortem é uma ferramenta fundamental no processo de identificação em Odontologia legal. Entretanto, essa técnica apenas pode ser aplicada com a existência de arquivos anteriores para comparação. Logo, é importante enfatizar a importância da manutenção e do correto arquivamento de exames de imagens odontológicos obtidos durante o tratamento do paciente, pelos cirurgiões-dentistas.

Descritores: Odontologia Legal; Radiografia Dentária; Identificação de Vítimas.

\section{Abstract}

Introduction: Dental imaging is of great relevance for human identification, and is often used by Legal Dentistry for this purpose. The correct archiving of imaging tests in patients' medical records allows the purchase of ante and post mortem data. Objective: This study aimed to describe the determination of the identification of a charred individual through dental imaging. Case report: The documentation provided by the victim's family was one was compared with those obtained by periapical radiographs of the teeth performed by the experts. The following coincident points were found after the comparison of information between antemortem and post-mortem examinations: gyroversion of tooth 34,43 and 44 ; secondary dentin in the pulp chambers of teeth $36,37,46,47$ and 48 ; occlusal caries of tooth 36 and bone trabeculate with individual anatomical characteristics in the region of lower molars on the right and left sides, resulting in a positive identification. Conclusion: Thus, it is concluded that the confrontation between antemortem and post-mortem radiographs is a fundamental tool in the process of identification in legal dentistry. However, this technique can only be applied with the existence of previous files for comparison. Therefore, it is important to emphasize the importance of maintaining and correct archiving dental imaging exams obtained during the treatment of the patient by dentists.

Descriptors: Forensic Dentistry; Radiography, Dental; Victims Identification.

\section{Resumen}

Introducción: Las imágenes dentales son de gran relevancia para la identificación humana, y a menudo es utilizada por la Odontología Legal para este propósito. El archivado correcto de las pruebas de diagnóstico por imágenes en los registros médicos de los pacientes permite la compra de datos ante y post mortem. Objetivo: Este estudio tenía como objetivo describir la determinación de la identificación de un individuo carbonizado a través de imágenes dentales. Informe del caso: La documentación proporcionada por la familia de la víctima fue comparada con la obtenida por radiografías periapicales de los dientes realizadas por los expertos. Se encontraron los siguientes puntos coincidentes después de la comparación de la información entre los exámenes antemortem y post mortem: giroversión del diente 34, 43 y 44; dentina secundaria en las cámaras de pulpa de los dientes 36, 37, 46, 47 y 48; Caries oclusales del diente 36 y trabeculado óseo con características anatómicas individuales en la región de molares inferiores en los lados derecho e izquierdo, lo que resulta en una identificación positiva. Conclusión: Así, se concluye que la confrontación entre las radiografías antemortem y post mortem es una herramienta fundamental en el proceso de identificación en la odontología jurídica. Sin embargo, esta técnica sólo se puede aplicar con la existencia de archivos anteriores para la comparación. Por lo tanto, es importante destacar la importancia de mantener y corregir el archivado de exámenes de imágenes dentales obtenidos durante el tratamiento del paciente por los dentistas.

Descriptores: Odontología Forense; Radiografía Dental; Identificación de Víctimas.

INTRODUÇ̃̃O

A Ciência Forense versa sobre a aplicação de métodos e processos científicos derivados das mais diversas áreas de estudo com o objetivo de solucionar situações não somente criminais, mas jurídicas ${ }^{1}$. Dentre as demandas atribuídas à Ciência Forense está o processo de identificação humana, método científico usado para se determinar a identidade de um indivíduo a partir de elementos antropométricos e antropológicos ${ }^{2,3}$. 
Nesse viés, sabe-se que os métodos de identificação humana podem ser classificados em primários (papiloscopia, análise de DNA e de dados odontológicos) e secundários (reconhecimento facial, roupas, dados médicos e outros), sendo que esses não podem ser usados isoladamente na determinação da identidade, logo, são usados para reforçar a identificação estabelecida por outros métodos ${ }^{4}$. Sendo assim, em razão da sua aplicabilidade, os procedimentos de identificação de humana vêm ocupando papel de destaque dentre os exames periciais médico e odontolegais ${ }^{5}$.

No âmbito da Odontologia Legal, a identificação humana se torna possível por meio da obtenção de informações odontológicas ante-mortem, como radiografias dentais, modelos em gesso, fotografias do sorriso e prontuários odontológicos. Tal instrumento, cuja elaboração compete ao cirurgião-dentista, expõe os procedimentos dentários realizados no paciente, sendo, dessa maneira, de extrema importância legal, possibilitando a análise comparativa entre as informações ante-mortem do indivíduo e os dados post-mortem, os quais podem ser obtidos pelos exames radiológicos dos arcos dentários ${ }^{6,7}$.

O conhecimento das imagens radiográficas dos arcos dentais é de grande importância para a identificação humana pela Odontologia Legal, por isso, se torna relevante o correto arquivamento dos prontuários dos pacientes, de tal forma que a análise comparativa entre os dados seja possível e, dessa forma, a identificação do indivíduo ${ }^{8}$. Contudo, ressalta-se que essa comparação somente é possível em razão da perenidade e da resistência, intrínsecas dos dentes, cuja análise ainda é viável mesmo em situações em que as vítimas se encontram carbonizadas, esqueletizadas ou em avançado estágio de decomposição ${ }^{9,10}$.

Diante do exposto, o presente trabalho objetivou descrever a determinação da identificação de um indivíduo carbonizado por meio da imaginologia odontológica.

CASO CLÍNICO

O presente relato de caso teve a aprovação do comitê de ética e pesquisa, sob o número de CAAE: 98398718.0.0000.5181 e número do parecer final: 3.137.019. Aos 30 dias do mês de março do ano de 2015, foi encaminhado ao Instituto Médico Legal Afrânio Peixoto (IMLAP) do Departamento de Polícia Técnico-Científica do Estado do Rio de Janeiro um corpo carbonizado, não identificado, para que se procedesse à perícia de identificação odontolegal (Figuras 1 e 2).

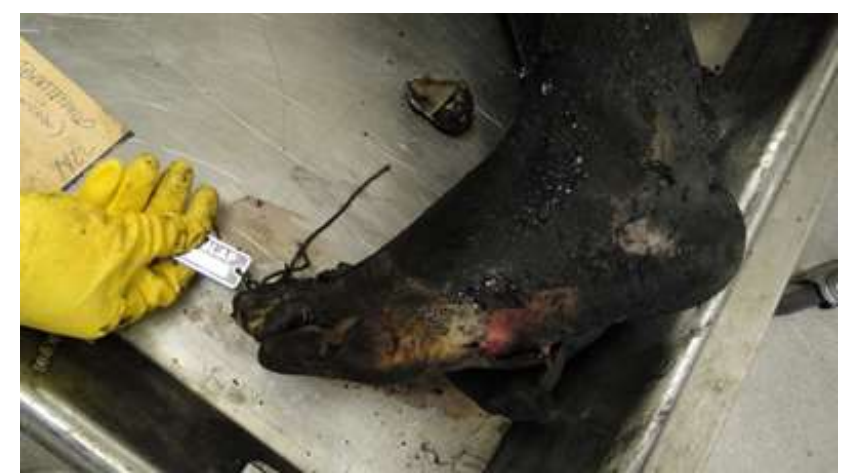

Figura 1: Membro inferior esquerdo do individuo carbonizado (Fonte: IMLAP)

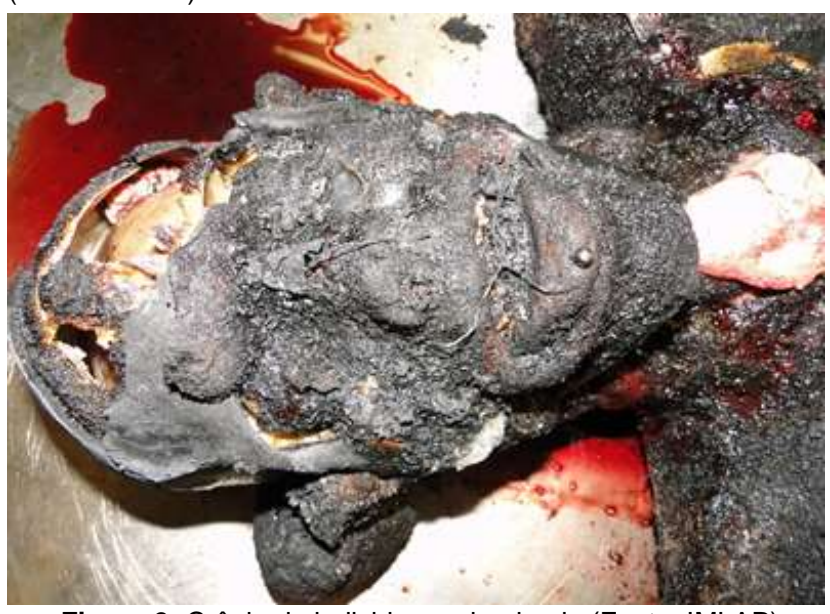

Figura 2: Crânio de individuo carbonizado (Fonte: IMLAP) Inicialmente,

foram

realizadas

radiografias periapicais nas regiões de canino inferior direito e molares inferiores, direitos e esquerdos que, de interesse pericial, revelaram giroversão dos dentes 34, 43 e 44; aposição de dentina secundária nas câmaras pulpares dos dentes 36, 37, 46, 47 e 48; cárie oclusal no dente 36 ; trabeculado com características anatômicas individuais em região de molares inferiores nos lados direito e esquerdo e inclusão em tecido mole do dente 48. Além disso, o cadáver ainda apresentava piercing lingual prateado e de metal em forma de halter (Figuras 3 e 4).

Em seguida, foram levantados dados de exames odontológicos ante-mortem fornecidos pela família, como uma radiografia panorâmica datada de 2014 e uma declaração de 2015. O primeiro exame revelava giroversão dos dentes 34, 43 e 44; ausência de restaurações; aposição de dentina secundária nas câmaras pulpares dos dentes 36, 37, 46, 47 e 48; inclusão em tecido mole do dente 48; cárie oclusal do dente 36 e trabeculado com características anatômicas individuais em região de molares inferiores nos lados direito e esquerdo. Por sua vez, a declaração datada do dia 30/03/2015 mostrava a presença de todos os elementos dentais, desvio de linha média inferior para direita, com apinhamento superior e inferior no lado direito, sem nenhuma lesão óssea ou radicular (Figura 5). 


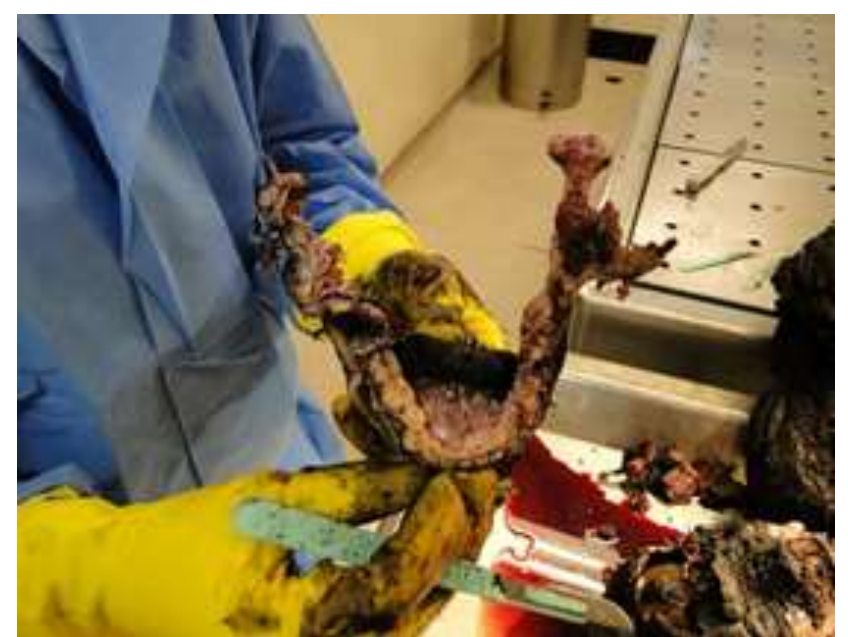

Figura 3: Mandíbula com piercing lingual (Fonte: IMLAP)

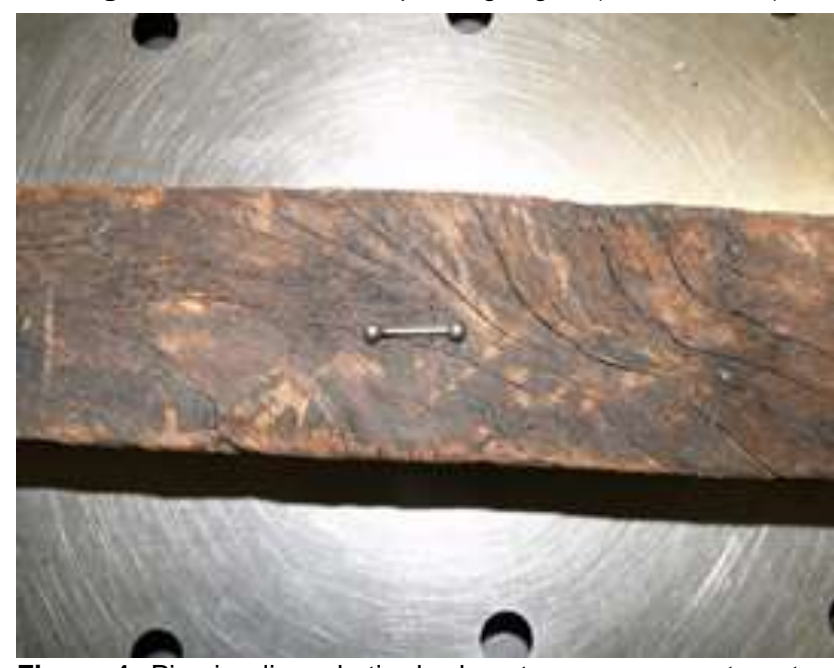

Figura 4: Piercing lingualretirado durante o exame post-mortem. (Fonte: IMLAP)

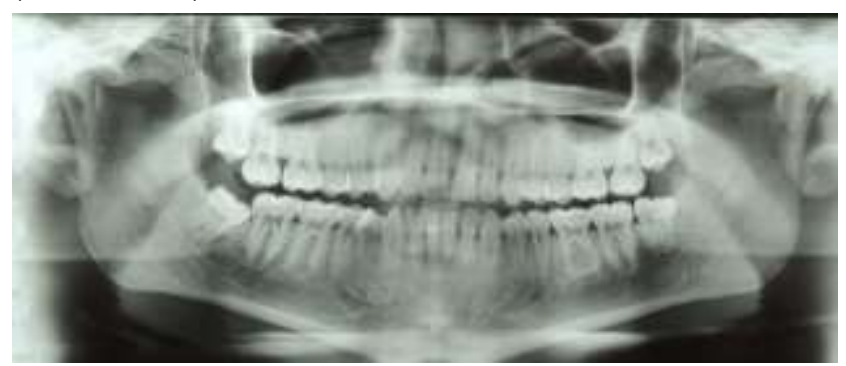

Figura 5: Radiografia panorâmica dos maxilares do ano de 2014. (Fonte: Exame cedido pelo cirurgião-dentista)

Sendo assim, foi realizada a análise comparativa entre os resultados de tais exames com aqueles encontrados no exame radiográfico efetuado pelos peritos, a qual permitiu constatar compatibilidade dos aspectos anatômicos, morfológicos, fisiológicos, e nos procedimentos odontológicos propostos e realizados. Foram encontrados os seguintes pontos coincidentes após o confronto das informações entre os exames ante-mortem e post-mortem: giroversão dos dente 34, 43 e 44; aposição de dentina secundária nas câmaras pulpares dos dentes 36, 37, 46, 47 e 48; cárie oclusal do dente 36 e trabeculado ósseo com características anatômicas individuais em região de molares inferiores nos lados direito e esquerdo,possibilitando,

portanto, a identificação positiva do indivíduo carbonizado (Figura 6).

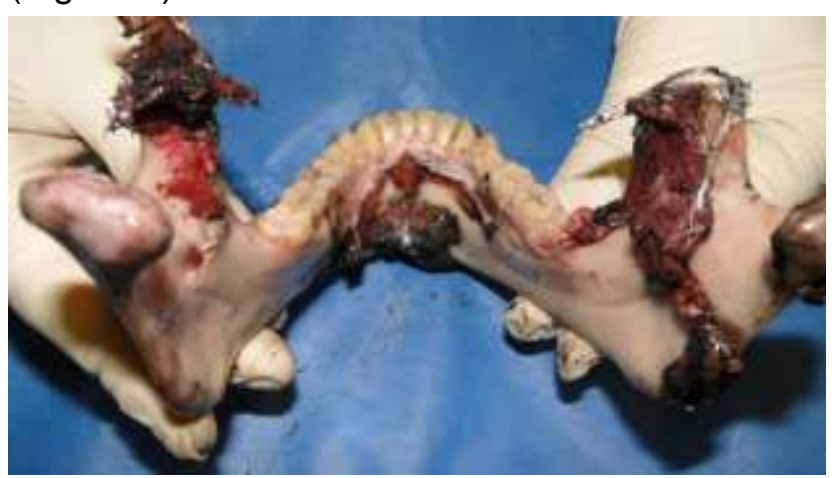

Figura 6: Mandíbula mostrando características post-mortem: cárie oclusovestibular no elemento 36; giroversão dos dentes 34,43 e 44; lingualização do elemento 45 e vestibularização do 44.

DISCUSSÃO

O presente relato de caso descreveu o processo de identificação humana de um indivíduo do sexo masculino carbonizado, realizado por meio da comparação de uma radiografia odontológica (obtida intra-vitam, contida no prontuário odontológico registrado) e achados radiográficos post-mortem dos arcos dentários do indivíduo.

A identificação humana por meio da comparação entre exames radiográficos postmortem e as documentações previamente fornecidas dos arcos dentais da vítima, é de extrema relevância para a prática pericial, sobretudo em corpos carbonizados ${ }^{7,10,11}$. Esse método primário de identificação humana, mesmo em situações adversas, só se torna viável porque os dentes são estruturas ósseas resistentes e de boa durabilidade e longevidade, o que habilita seu estudo mesmo em condições como: cadáveres esqueletizados, em estágio avançado de decomposição ou cadáveres carbonizados como descrito no presente relato de caso pericial ${ }^{9-11}$.

Dessa forma, o perito deve ter em sua posse a documentação odontológica prévia da vítima $^{12}$. Por isso, a necessidade do registro anterior confere uma das desvantagens desse método, uma vez que as informações disponíveis podem ser de má qualidade ou insuficientes para determinar a identidade da vítima, levando a um resultado inconclusivo ${ }^{7}$.

Além do resultado inconclusivo, o manual da American Board of Forensic Odontology (2011) considera outras conclusões no que concerne à identificação humana, as quais são: identificação positiva - quando os dados ante e post-mortem forem concordantes e com detalhes suficientes, bem como desprovida de discrepância inexplicável; e identificação possível - quando existem 
características semelhantes, porém não se pode confirmar com convicção que são totalmente compatíveis. Tal método primário de identificação humana é dividido didaticamente em três fases: exames dos arcos dentários do cadáver, análise das documentações odontológicas prévias (possíveis tratamentos, piercings, lugares de bracketes, desgaste, anatomia das ceúspides) e o confronto odontolegal ${ }^{7,13}$.

No presente caso, as documentações fornecidas pela família da vítima foram uma declaração do cirurgião-dentista e uma radiografia panorâmica cujas informações foram confrontadas com aquelas obtidas pelas radiografias periapicais dos dentes realizadas pelos peritos.

Dessa forma, percebe-se a importância dos exames de imagem, os quais proporcionam ao cirurgião-dentista informações confiáveis e nem sempre perceptíveis ao exame clínico, sendo essas informações imprescindíveis para o processo de identificação humana ${ }^{5}$.

CONCLUSÃO

Há inúmeras técnicas radiográficas que podem ser utilizadas para auxiliar na identificação humana. Como relatado, o confronto entre as radiografias ante-mortem e post-mortem tornou-se uma ferramenta fundamental no processo de identificação em Odontologia legal. Todavia, essa técnica apenas pode ser aplicada com a existência de arquivos anteriores para comparação. Logo, é importante enfatizar a importância da manutenção e do correto arquivamento de exames de imagens odontológicos obtidos durante o tratamento do paciente, pelos cirurgiões-dentistas.

\section{REFERÊNCIAS}

1. Furtado GD, Sobral FES, Silva AS, Quirino AHL, Sampaio ACA. Radiologia forense e sua atuação: uma breve revisão. Environmental Smoke. 2018;1(2):110-19.

2. De França GV. Medicina legal. Rio de Janeiro: Guanabara Koogan; 2017.

3. Vanrell JP. Odontologia Legal e Antropologia Forense, 2. ed. Rio de Janeiro: Guanabara Koogan; 2009.

4. Figueira Junior $E$, De Moura LCL. A importância dos arcos dentários na identificação humana. Rev bras odontol. 2014;71(1):22-7.

5. Carvalho SPM, Silva RHADS, Lopes JC, SalesPeres A. A utilização de imagens na identificação humana em odontologia legal. Radiol Bras. 2009; 42(2):125-30.

6. Da Silva RF, De La Cruz BVM, Daruge Jr. E, Daruge E, Francesquini Jr. LF. La importancia de la documentación odontologica en la identificación humana-relato de caso. Acta Odontol Venez. 2005;43(2):159-64.

7. Da Silva RF, Daruge Jr E, Pereira SDR, De Almeida SM. Identificação de cadáver carbonizado utilizando documentação odontológica. Rev Odonto Cienc. 2008;23(1): 90-3.

8. Coutinho CGV, Ferreira CA, Queiroz LR, Gomes LO, Silva UA. O papel do odontolegista nas perícias criminais. RFO UPF. 2014;18(2): 217-23.

9. Muller M, Berytrand MF, Quatrehomme G, Bolla M, Rocca JP. Macroscopic and microscopic aspects of incinerated teeth. J Forensic Odontostomatol. 1998;16(1):1-7.

10.Scoralick RA, Barbieri AA, Moraes ZM, Francesquini Júnior $L$, Daruge Júnior $E$, Naressi SCM. Identificação humana por meio do estudo de imagens radiográficas odontológicas: relato de caso. Rev Odontol UNESP. 2013;42(1):67-71.

11. Leite MM, Amorim AC, Gomes T, Prado M, Silva R. A importância da atuação do odontolegista no processo de identificação humana de vítimas de desastre aéreo. ROBRAC. 2011;20(52):52-8.

12. Figueira Jr E, Moura LCL. A importância dos arcos dentários na identificação Humana. Rev Bras Odontol. 2014;71(1):22-7.

13. Rothwell BR. Principles of dental identification. Dent Clin North Am. 2001;45(2):253-70.

\section{CONFLITO DE INTERESSES}

Os autores declaram não haver conflitos de interesse

\section{AUTOR PARA CORRESPONDÊNCIA}

\section{Rafaella Bandeira de Melo Souza Cavalcanti}

Curso de Odontologia

Universidade Federal de Campina Grande (UFCG)

58708-110 Patos - PB, Brasil

E-mail: rafaella.bm@hotmail.com 